\title{
THE IMPACT OF MALOLACTIC FERMENTATION ON THE VOLATILE COMPOSITION OF THE TRINCADEIRA WINE VARIETY
}

\author{
M. PIETRA TORRES ${ }^{1}$, M.J. CABRITA ${ }^{1,3}$, M.D.R. GOMES DA SILVA ${ }^{2}$, \\ V. PALMA ${ }^{1}$ and A.M. COSTA FREITAS ${ }^{1}$ \\ ${ }^{1}$ Departamento de Fitotecnia \\ Instituto Ciências Agrárias e Ambientais Mediterrânicas - ICAAM \\ Universidade de Évora \\ Apt 94 7002-554 Évora, Portugal \\ ${ }^{2}$ REQUIMTE \\ Departamento de Química \\ Faculdade de Ciências e Tecnologia \\ Universidade Nova de Lisboa \\ Campus da Caparica, 2829-516 Caparica, Portugal
}

Accepted for Publication August 22, 2009

\begin{abstract}
Use of commercial starters for malolactic fermentation (MLF) is a common practice, and outcomes of this procedure are very relevant for wine producers because aroma attributes might change according to the strain used.

MLF was carried out in the Trincadeira wine variety in three batches: spontaneously and with inoculation of two different commercial starters. Wine extracts before and after MLF were obtained through liquid-liquid extraction. Gas chromatography/ion trap mass spectrometry analysis allowed the detection of 21 compounds, some of them tentatively identified through electron impact spectra comparison with a database, through interpretation of multistage mass spectrometry and chemical ionization mass spectrometry spectra and confirmation by comprehensive multidimensional gas chromatography/ time of flight-mass spectrometry $(G C \times G C / T o F-M S)$.

After $M L F$, an increase in ethyl lactate, $\gamma$-butyrolactone and diethyl succinate and a drop in isoamyl acetate, ethyl octanoate, ethyl decanoate, 2,3-dimethyl-hexan-3-ol, propanol, isobutanol and 2,3-butanediol was observed. The concentrations of the 10 compounds are statistically different in wines before and after MLF, and wines after MLF show significant differences for the nine compounds.

${ }^{3}$ Corresponding author. TEL: +351-266-760869; FAX: +351-266-760828; EMAIL: mjbc@uevora.pt




\section{PRACTICAL APPLICATIONS}

The Trincadeira variety is broadly used in the production of red wine in the south region of Portugal. Nevertheless, little was published concerning this red wine variety in international literature, where most frequently, the analysis of the volatile constituents of Trincadeira is not the goal. Moreover, the evaluation of the malolactic fermentation (MLF) impact produced by indigenous or selected starter bacteria on the aroma composition of the wines produced with their grapes was never studied before. The interesting behavior of this variety during MLF described in this work might possibly explain the unique characteristics of the overall bouquet produced with it.

The main volatile compounds obtained after all three MLF processes were identified and quantified using gas chromatography/ion trap mass spectrometry, gas chromatography/chemical ionization mass spectrometry (GC/CI/MS) and gas chromatography/multistage mass spectrometry (GC/MS/MS) and standard coinjection. Comprehensive multidimensional gas chromatography $(\mathrm{GC} \times \mathrm{GC})$ was used for confirmation purposes in all cases where standards were not available in order to also validate the results obtained by $\mathrm{GC} / \mathrm{CI} / \mathrm{MS}$ and GC/MS/MS.

\section{INTRODUCTION}

The complex array of aroma compounds found in wine arises from grapes, yeast and bacterial metabolism during fermentation and/or from chemical or enzymatic reactions that take place during storage and aging.

Malolactic fermentation (MLF) takes place because of lactic acid bacteria (LAB), usually after alcoholic fermentation. The major processes involved are malic and citric acid metabolism. The main consequence of MLF is a decrease in total acidity as well as microbial stabilization; however, other subtler changes result in a higher complexity of the aroma (Gámbaro et al. 2001). Bacterial metabolism contributes to the aroma either by transformation of grape- or yeast-derived compounds or by formation of additional ones (Lonvaud-Funel 1999; Revel et al. 2005; Ugliano and Moio 2005).

The most observed aroma modification is the increase in the buttery character associated with diacetyl content (butan-2,3-dione). However, MLF can also be responsible for changes in fruity, floral, nutty and herbaceous attributes (Sauvageot and Vivier 1997; Gámbaro et al. 2001).

Compounds and mechanisms responsible for these complex changes are not well known; it was already suggested that acetaldehyde and/or other aldehyde's degradation by LAB contribute to the reduction of herbaceous aroma (Osborne et al. 2000). Additionally, LAB produce other odorant com- 
pounds as fusel alcohols, fatty acids, lactones, sulphur and nitrogen compounds (Ugliano and Moio 2005) that might have an impact on aroma.

Wine aroma is one of the major features that allows differentiation, characterization and qualification of the numerous wines all over the world. One of the several tools available for winemaking is the selection of microbial starters to carry out fermentation, seeking to optimize the aroma compound's biosynthesis without affecting overall fermentation (Swiegers et al. 2005). For MLF, Oenococcus oeni strains are usually predominant because of their tolerance to adverse wine conditions.

The study of different starters are very relevant for wine producers because the volatile composition, and thus the resulting attributes, might change according to the strain used for MLF (Gámbaro et al. 2001; Gindreau et al. 2003; Pozo-Bayon et al. 2005; Revel et al. 2005).

Determining volatile compounds in wine requires an extraction step (liquid-liquid extraction, solid phase extraction, supercritic fluid extraction, solid phase microextraction, etc.) (Karagiannis et al. 2000; Ortega-Heras et al. 2002; Karásek et al. 2003; Rocha et al. 2006), followed by gas chromatography (GC) for analytes separation. Gas chromatography in tandem with mass spectrometry (GC/MS) has been widely used for separation and detection of food aroma compounds (Careri et al. 2002). Generally, electron impact (EI) ionization is used for identification of the volatile fraction compounds, but multistage mass spectrometry (MS/MS) experiments to obtain structure-specific fragmentation of compounds and chemical ionization (CI) to confirm/verify the molecular mass of a particular compound are very useful tools as well.

Therefore, for tentative identification, the spectra obtained after EI mode are compared with a database. This is, in general, the first assumption for peak identification. When available, one can also use additional tools such as CI mode, MS/MS and standard coinjection when standards are available. EI mode allows a rapid identification of compounds present, but as ions resulting form EI mode can also be formed because of ion-molecule reactions, thus extending fragmentation patterns, low structure specificity ions might be obtained (Benincasa et al. 2003). CI mode with methane as reagent gas may provide a relatively abundant $[\mathrm{M}+\mathrm{H}]^{+}$, and on the other hand, MS/MS can provide cleaner spectra and further knowledge about the ion's origin. Both methods produce lower fragmentation profiles than EI mode. This fact might be significant for the specific identification of fragment ions and supporting structural information (Benincasa et al. 2003; Bouchonnet et al. 2004; Culleré et al. 2006). GC $\times$ GC experiments, on the other hand, are increasingly applied for complex matrix characterization (Adahchour et al. 2008). When in tandem with mass spectrometric detectors, high resolution and sensitivity is attained, and nearly pure spectra are produced, thus facilitating the identification task (Cardeal et al. 2006; Mateus et al. 2008). 
The purpose of this study was to determine and identify volatile compounds in red wine from a Portuguese red wine variety, Trincadeira, which is broadly used in the production of red wine in the south region of Portugal. This variety is the most ancient and traditional grape variety of the Alentejo region, very well adapted to the climatic conditions and represents a large fraction in vineyards. Nevertheless, little is known about the volatile profile of wines produced with Trincadeira grapes, and as far as the authors are aware, the evaluation of the MLF impact produced by indigenous or selected starter bacteria on the aroma composition of the wines produced with their grapes was never studied before.

The majority of the identified compounds were confirmed by standard coinjection, and for the tentative identification of some compounds, gas chromatography/ion trap mass spectrometry (GC/ITMS) analysis was used, either in EI or CI mode and also through MS/MS results interpretation. Comprehensive multidimensional gas chromatography/Time of Flight-Mass spectrometry $(\mathrm{GC} \times \mathrm{GC} / \mathrm{ToF}-\mathrm{MS})$ was used in order to confirm the identification assignments.

\section{EXPERIMENTAL}

\section{Reagents and Standards}

Dichloromethane chromatography grade and anhydrous sodium sulfate, phosphoric acid and $\mathrm{NaOH}$ analytical grade were supplied by Merck (Darmstadt, Germany); absolute ethanol was supplied by Panreac (Barcelona, Spain). The water used was bidistilled and passed through a Milli-Q system (Millipore, Bedford, MA).

The standards used were as follows: propanol, isoamyl acetate (>98\%) isoamyl alcohol, ethyl hexanoate (>98\%), ethyl lactate $(>99 \%)$, hexanol $(>98 \%)$, ethyl octanoate (>98\%), butan-2,3-diol (>99\%), $\gamma$-butyrolactone $(>99 \%)$, diethyl succinate $(>98 \%)$, octanoic acid $(>99 \%)$, decanoic acid $(>98 \%)$, lactic acid (>99\%) and malic acid (>99.5\%) supplied by Merck, and isobutanol (>99\%), 3-octanol (>99\%) and phenylethanol (>99\%) all supplied by Extrassynthése (Genay, France).

\section{Wine Samples Preparation}

Trincadeira grapes were manually harvested from the whole vineyard to obtain a representative sample at maturity $(\mathrm{pH}=3.57$; total acidity $=5.23 \mathrm{~g} / \mathrm{L}$ $\mathrm{TH}_{2}$; soluble solid content of $22.6^{\circ} \mathrm{Brix}$ ). The grapes were destemmed and crushed using the appropriate apparatus, and $150 \mathrm{mg} / \mathrm{L}$ of $\mathrm{SO}_{2}$ was added to the must. The inoculation took place with activated yeast Fermol A3B $(200 \mathrm{mg} / \mathrm{kg}$ ) from AEB (Brescia, Italy). Alcoholic fermentation was carried 


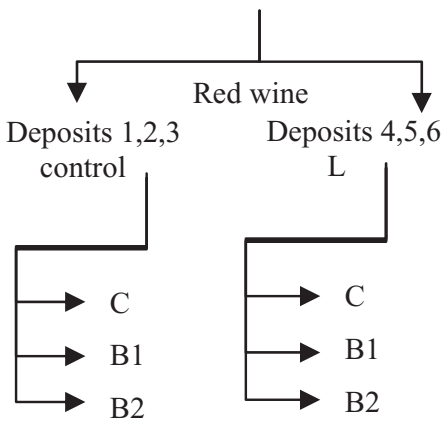

FIG. 1. VINIFICATION SCHEME

Deposits 1-6 are 60-L vessels where alcoholic fermentation took place. Each deposit was divided into three: $\mathrm{C}, \mathrm{B} 1$ and B2 identify the $15-\mathrm{L}$ vessels where malolactic fermentation took place.

C, control; L, Lysocid; B1, Biolact Acclimatée; B2, Biolact Acclimatée 4R.

out in $6 \times 60$-L stainless steel tanks (deposits 1-6) (half of them added with lisozyme - $200 \mathrm{mg} / \mathrm{kg}$ - Lysocid from AEB - to delay MLF; deposits 4-6), and the fermenting musts were punched down twice a day. The control was performed by density and temperature (around 28C) measurements in order to preserve the same evolution in all the tanks. After alcoholic fermentation (7 days of pomace), both press and free-run wines were assembled and the wine from each tank (deposits 1-6) was distributed among $3 \times 15$-L glass carboys. In the three batches, MLF was carried out by indigenous bacteria in the first carboy (identified as C) and commercial starters of O. oeni were inoculated $(5 \mathrm{mg} / \mathrm{L})$ after activation in the other two: Biolact Acclimatée (AEB) identified as B1 and Biolact Acclimatée 4R (AEB) identified as B2. This makes a total of 18 experiments, plus six samples before MLF, for a total of 24 samples The vinification scheme is shown in Fig. 1.

\section{Malic and Lactic Acid High-performance Liquid Chromatography (HPLC) Determination}

Malolactic fermentation was followed through the determination of malic and lactic acid in wine samples according to previously reported methodology (Cane 1990; Cabrita et al. 2008) using an HPLC apparatus from HewlettPackard series 1050 with a quaternary pump and a Hewlett-Packard diode array detector series 1100 (Agilent Technologies, Waldbronn, Germany), equipped with a LichroCART ${ }^{\circledR} 250-4$ Superspher ${ }^{\circledR}$ RP 18 endcapped column $(5 \mu \mathrm{m}$ packing, $250 \mathrm{~mm} \times 4.6 \mathrm{~mm}$ i.d.) (Merck). The mobile phase was phosphoric acid $\left(5 \times 10^{-3} \mathrm{M}\right)$, flow $0.7 \mathrm{~mL} / \mathrm{min}$, and detection was performed at $210 \mathrm{~nm}$. Sample preparation includes the extraction with a Sep-Pak ${ }^{\circledR}$ cartridge C18 $300 \mathrm{~g}$ (Waters, Milford, MA) of wine diluted 1:2 with phosphoric acid $1 \mathrm{M}$ and 
recovered with phosphoric acid $5 \times 10^{-3} \mathrm{M}$. Calibration curves were established for the two acids in a range between 4 and $0.1 \mathrm{~g} / \mathrm{L}$, with correlation coefficients of 0.999 and 0.998 for malic and lactic acids, respectively (for $n=6$ ). The limit of detection (LOD) and the limit of quantification (LOQ) limits were established according to Miller and Miller (1993): for malic acid LOD $=0.051 \mathrm{~g} / \mathrm{L}$ and $\mathrm{LOQ}=0.259 \mathrm{~g} / \mathrm{L}$, and for lactic acid $\mathrm{LOD}=0.048 \mathrm{~g} / \mathrm{L}$ and $\mathrm{LOQ}=$ $0.573 \mathrm{~g} / \mathrm{L}$. Wine samples were collected from day 0 of MLF and every 3 or 4 days, until no malic acid was detected. All samples were done in duplicate.

\section{Extraction of Volatile Compounds}

Wine samples were collected before and after MLF was completed and were stored at $-32 \mathrm{C}$ until extraction. Volatile compounds were obtained in duplicate after liquid-liquid extraction with dichloromethane: $2 \mathrm{~mL}$ of internal standard octan-3-ol (60 mg/L in ethanol 75\%) was added to $50 \mathrm{~mL}$ of wine; the $\mathrm{pH}$ was adjusted to 7.5 by adding $\mathrm{NaOH}$. Extraction was performed stepwise with $5,2.5$ and again $2.5 \mathrm{~mL}$ of dichloromethane. The organic extracts were concentrated up to $0.5 \mathrm{~mL}$ under a gentle stream of nitrogen.

\section{GC Analysis}

GC-Flame Ionization Detector (FID). A Hewlett-Packard 6890 gas chromatograph equipped with an FID (Agilent Technologies) was used for quantification. One microliter of sample was injected in splitless mode. Splitless time was set at $30 \mathrm{~s}$. Injector and detector temperatures were 250C. A polyethylenoglycol capillary column, RTX-Wax $(60 \mathrm{~m} \times 0.25 \mathrm{~mm}$ ID and $0.25 \mathrm{~mm}$ film thickness; Restek, Bellefonte, PA), was used as analytical column. Oven temperature program was as follows: $45 \mathrm{C}$ for $1 \mathrm{~min}$, increased to $230 \mathrm{C}$ at $3 \mathrm{C} / \mathrm{min}$ and held for $25 \mathrm{~min}$, the carrier gas was helium at constant pressure (18 psi). HP chemstation software (Agilent Technologies) was used for data acquisition. For quantification purposes, when standards were available, response factor were calculated; otherwise, semiquantitative analyses were performed assuming response factor is equal to one.

One-Dimensional (1D)-GC/ITMS. A Trace GC-Polaris Q ion trap mass spectrometer (Thermo Finnigan, Austin, TX) was used, with the transfer line at $250 \mathrm{C}$ and ion trap at 220C. For 1D chromatographic separation, the same conditions described for GC-FID analysis were used. EI/MS full scan was performed using $70 \mathrm{eV}$ in the mass range of 20-300 u (2.6 scan/s). Compounds were identified through comparison with standards when available; otherwise, besides comparison of MS spectra with the National Institute of Structures and Technology (NIST 2.0) library (quality match over 850 per- 
formed by Excalibur software), CI with methane as reagent gas at $3 \mathrm{~mL} / \mathrm{min}$ and MS/MS experiments were performed.

1D-GC/MS/MS. The same equipment and chromatographic conditions were used in MS/MS mode, where the collision energy was $1.0 \mathrm{~V}$ and resonance excitation was $q=0.30$. The parent ions were selected regarding their relative abundance and the structural information that they might provide; the acquisition method was time programmed in five time segments: from 22.9 to $23.5 \mathrm{~min}$, parent ions $(\mathrm{m} / \mathrm{z}) 73$ and 88 ; from 33.3 to $33.6 \mathrm{~min}$, parent ions $(\mathrm{m} / \mathrm{z})$ 87, 117 and 132; from 41.5 to $42.45 \mathrm{~min}$, parent ions $(\mathrm{m} / \mathrm{z})$ 73, 88 and 106; from 42.45 to $43.0 \mathrm{~min}$, parent ions $(\mathrm{m} / \mathrm{z}) 88,100$ and 130 ; from 45.0 to $46.0 \mathrm{~min}$, parent ions $(\mathrm{m} / \mathrm{z}) 33$ and 130 .

GC $\times$ GC/ToF-MS. The GC $\times$ GC/ToF-MS system consisted of an HP 6890 (Agilent Technologies, Burwood, Australia) gas chromatograph and a Pegasus III time-of-flight mass spectrometer (Leco, St. Joseph, MI). The modulator used was a longitudinally modulated cryogenic system (Chromatography Concepts, Doncaster, Australia) and was operated at a modulation period of $6 \mathrm{~s}$, with a cryotrap temperature of $-20 \mathrm{C}$. The ToF-MS was operated at a storage rate of $100 \mathrm{~Hz}$, using a mass range of $40-415 \mathrm{u}$ and a multichannel plate voltage of $1,400 \mathrm{~V}$. Data were processed using Leco Corp. Chro$\mathrm{maTOF}^{\mathrm{TM}}$ software. The column sets used for $\mathrm{GC} \times \mathrm{GC}$ experiments comprised of a BPX50 (50\% phenyl-dimethyl polysilphenylene-siloxane phase) primary column; $30 \mathrm{~m} \times 0.25 \mathrm{~mm}$ i.d. $\times 0.25 \mu \mathrm{m}$ film thickness (d.f.), directly -coupled to a BPX5 (50\% phenyl-dimethyl polysilphenylene-siloxane phase) second column of $1.0 \mathrm{~m} \times 0.1 \mathrm{~mm}$ i.d. $\times 0.1 \mu \mathrm{m}$ d.f. Both columns were from SGE International (Ringwood, Australia). The oven temperature program began at $40 \mathrm{C}$, held for $1 \mathrm{~min}$ and was then raised to $210 \mathrm{C}$ at $3 \mathrm{C} / \mathrm{min}$, then to $240 \mathrm{C}$ at $40 \mathrm{C} / \mathrm{min}$ and held for $10 \mathrm{~min}$ at this temperature. Helium was used at a flow rate at $1.3 \mathrm{~mL} / \mathrm{min}$. The interface column for the $\mathrm{GC} \times \mathrm{GC} / \mathrm{ToF}-\mathrm{MS}$ system was a $0.50 \mathrm{~m}$ deactivated fused silica column with $0.1 \mathrm{~mm}$ i.d. $(0.21 \mathrm{~m}$ inside the transfer line and $0.29 \mathrm{~m}$ inside the oven) from SGE International.

Because of the separation power allowed by $\mathrm{GC} \times \mathrm{GC}$, one could confirm, in tandem with ToF-MS, the identification assignments performed by 1D-GC. The compound identification task performed by the ChromaTOF ${ }^{\mathrm{TM}}$ software considered a spectra quality match of over 850 .

\section{Statistical Analysis}

Differences in volatile compounds present in wine before and after MLF was performed under different conditions (C, B1 and B2) were assessed by one-way analysis of variance; mean comparisons were performed using Fish- 

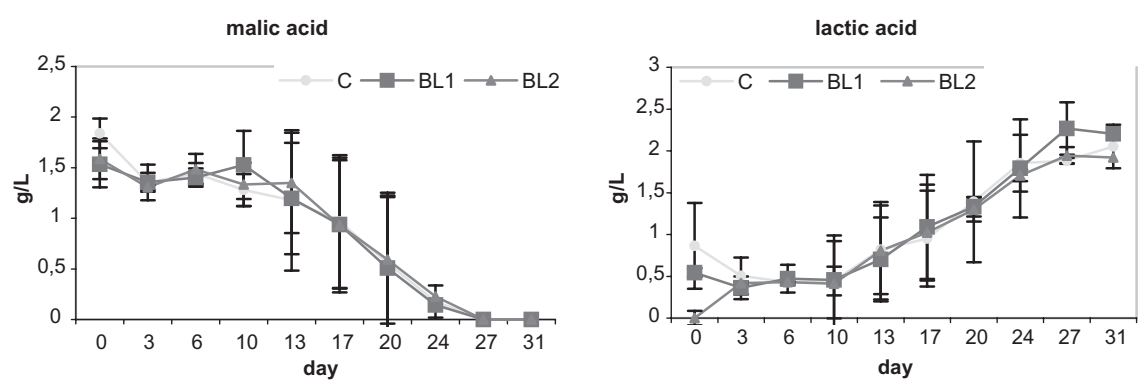

FIG. 2. MALIC AND LACTIC ACIDS CONCENTRATION EVOLUTION DURING

MALOLACTIC FERMENTATION (MLF)

C, MLF carried out by indigenous bacteria; BL1, MLF carried out with inoculation of B1; BL2, MLF carried out with inoculation of B2.

er's multiple comparison test at the $95 \%$ confidence level. Analyses were accomplished using NCSS 6.0 software (Statistical \& Power Analysis software, Kaysville, UT).

\section{RESULTS AND DISCUSSION}

\section{Malic Acid Degradation}

The evolution of malic and lactic acid concentration was followed by HPLC in order to provide information about the stage of the MLF in all studied samples (Fig. 2). The evolution profile of MLF was very similar regardless of the lactic bacteria used to perform the MLF. Although it could be expected that wines with commercial lactic bacteria (BL1 and BL2) would complete MLF quicker, this was not observed for the Trincadeira variety, which apparently indicate that this variety can perform MLF without the addition of lactic bacteria. The addition of lisozyme at the beginning of alcoholic fermentation did not affect MLF because it occurred in a very similar way in the sample wines fermented with and without lisozyme. Furthermore, one observed (results not shown) that lisozyme is only effective as an MLF inhibitor when added after alcoholic fermentation.

\section{Volatile Compounds Identified in Wine}

The volatile composition of the Trincadeira variety red wine before and after MLF carried out by indigenous bacteria (C) or with inoculation of B1 and B2, was analyzed by GC-FID (Fig. 3), and the main compounds identified are described in Table 1. Here, the most part of the volatile compounds found in the different extracts obtained after liquid extraction were identified by standard 


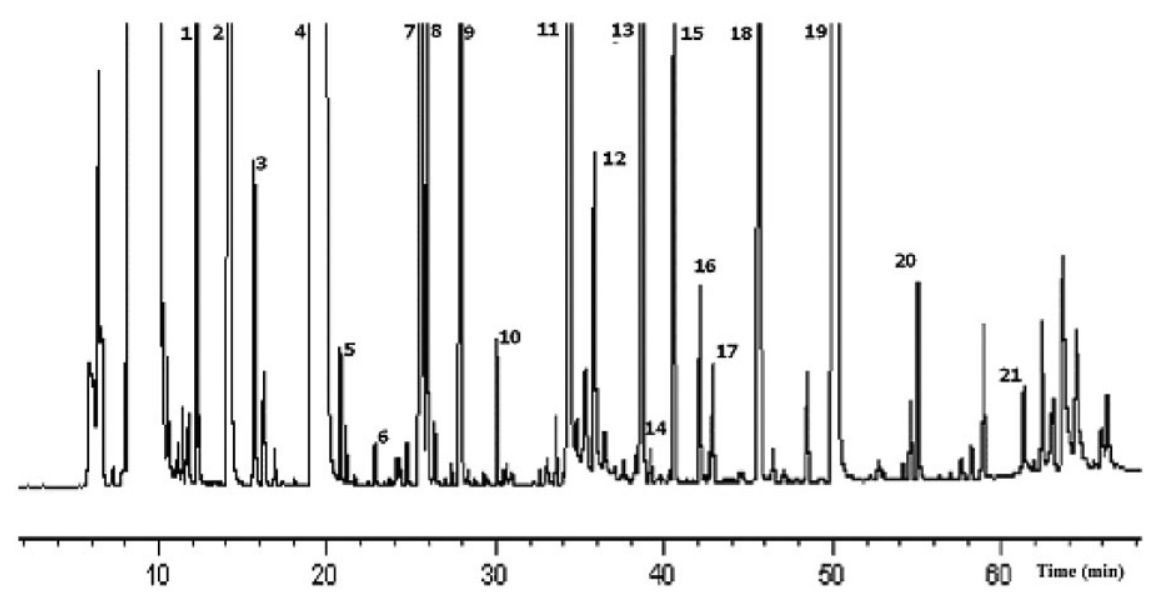

FIG. 3. GAS CHROMATOGRAPHY-FID CHROMATOGRAM OF A RED WINE EXTRACT AFTER MALOLACTIC FERMENTATION CARRIED OUT BY INDIGENOUS BACTERIA See text for the analytical conditions.

coinjection after GC/ITMS. When standards were not available, the spectrum obtained by EI mode of a particular compound was compared with the NIST database, and a tentative identification was performed. One also considered the spectra obtained after performing GC/ITMS in CI mode, which allowed for the determination of the respective $[\mathrm{M}+\mathrm{H}]^{+}$ions, and after MS/MS additional structure information could be gathered as indicated in Table 1. For the sake of clarity, only the identification steps for 2,3-dimethyl-hexan-3-ol are described: after EI ionization, the spectrum shown in Fig. 4a was obtained. The library search gave 2,3-dimethyl-hexan-3-ol as a possible match among other nonplausible possibilities. Although the fragmentation pattern shows the ions $\mathrm{m} / \mathrm{z}$ 115, $\mathrm{m} / \mathrm{z} 87$ (base peak) and $\mathrm{m} / \mathrm{z} 43$ expected through the losses of $\mathrm{H}_{2} \mathrm{O},-\mathrm{CH}_{3}$ and $-\mathrm{C}_{3} \mathrm{H}_{7}$, respectively, the molecular ion $\mathrm{m} / z 130[\mathrm{M}]^{+}$was not present. The molecular ion was later confirmed after GC/ITMS in CI mode with methane as reagent gas. The parent ions $m / z 130$ and $m / z 87$ were submitted to MS/MS as shown in Fig. 4b,c, respectively. Here, the analysis was performed in a mass range between 20 and $300 \mathrm{u}$ in order to allow the detection of the produced daughter ions potentially with $\mathrm{m} / \mathrm{z}$ values below $40 \mathrm{u}$. The expected losses of $\mathrm{H}_{2} \mathrm{O},-\mathrm{CH}_{3}$ and $-\mathrm{C}_{3} \mathrm{H}_{7}$ are observable in Fig. $4 \mathrm{~b}$, corresponding to the $m / z$ 112, $\mathrm{m} / \mathrm{z} 115$ and $\mathrm{m} / \mathrm{z}$ 87, and Fig. $4 \mathrm{c}$ shows the expected losses of $\mathrm{H}_{2} \mathrm{O}$ and $-\mathrm{C}_{3} \mathrm{H}_{7}$, corresponding to $\mathrm{m} / \mathrm{z} 69$ and $\mathrm{m} / \mathrm{z}$ 43. These facts add some evidence about the tentative identification proposed. Additionally, $\mathrm{GC} \times \mathrm{GC} / \mathrm{ToF}-\mathrm{MS}$ was performed in order to confirm the tentative assignment purposed for this compound, where a positive match was only considered when above 850 . This value 


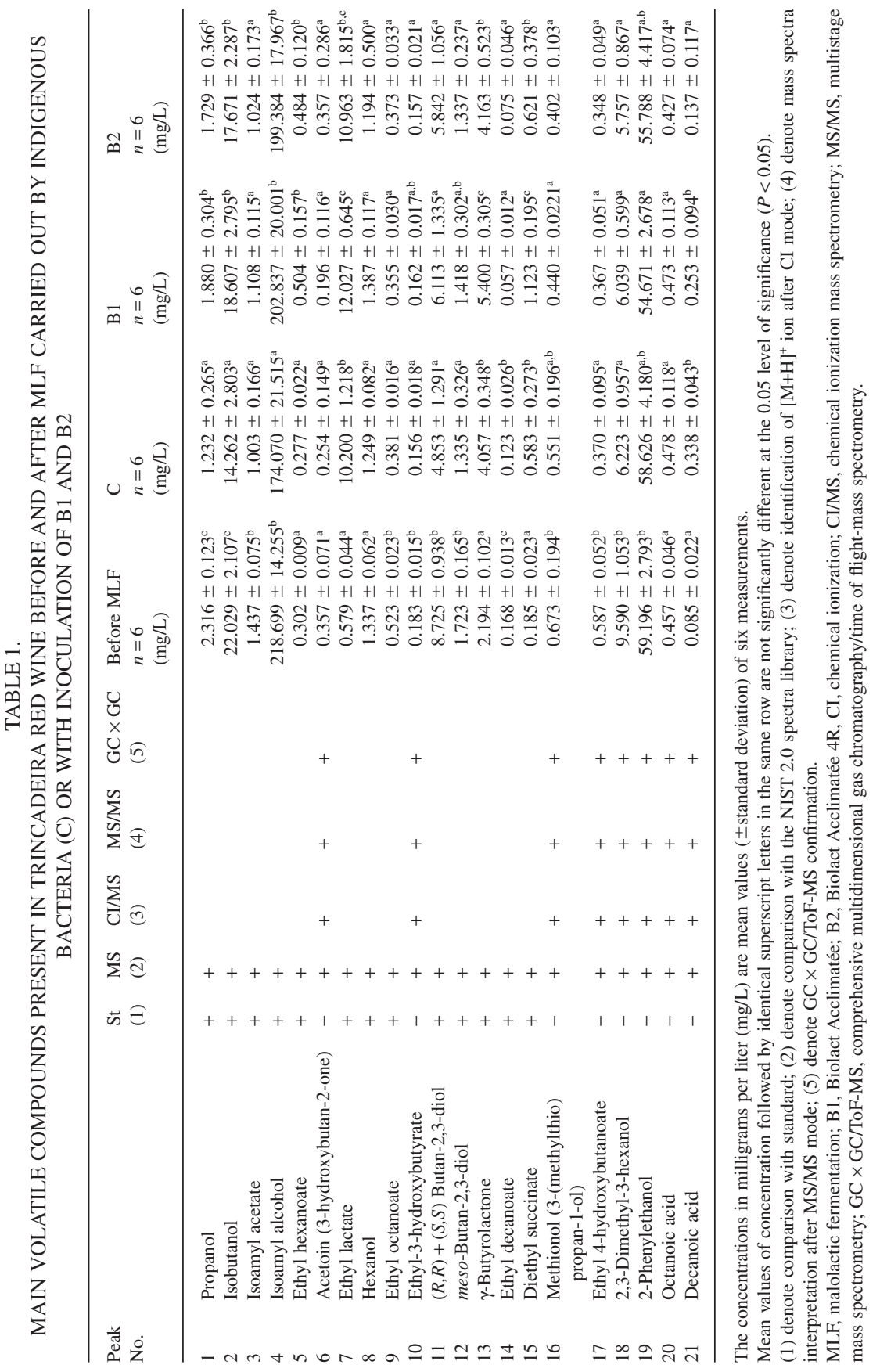



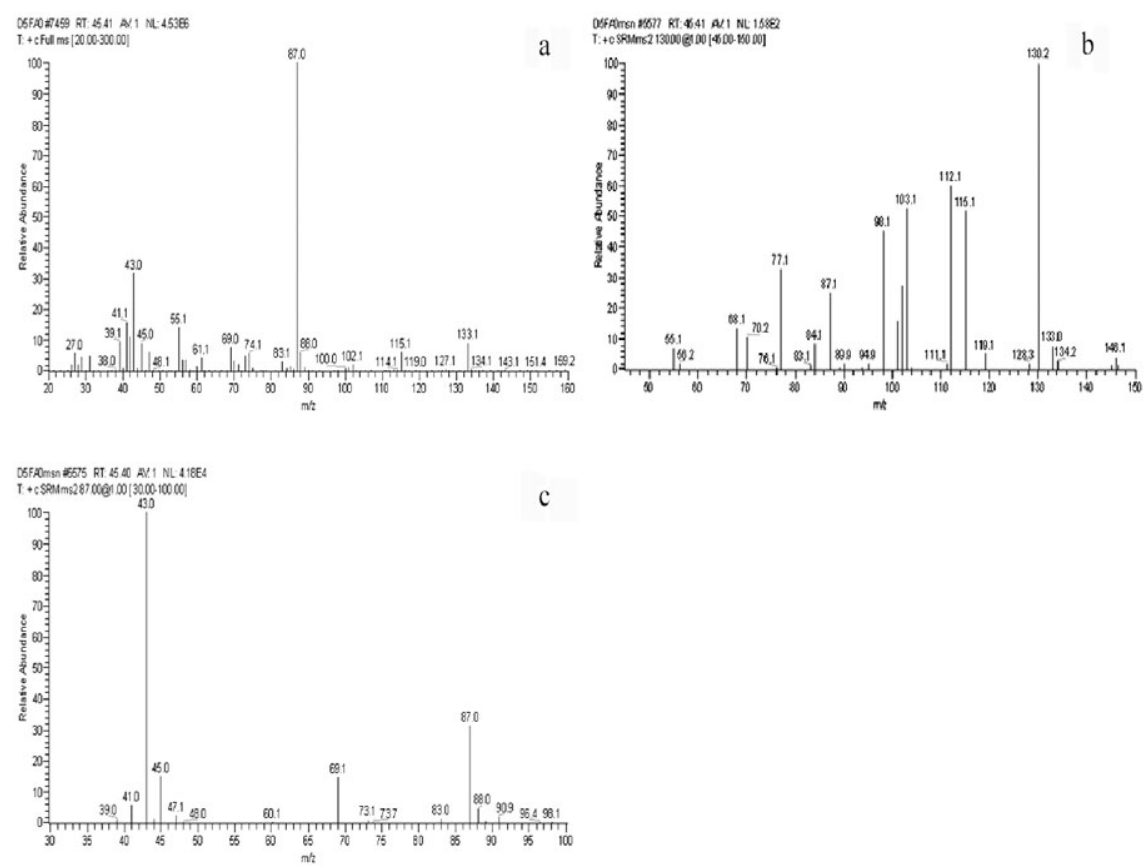

FIG. 4. 2,3-DIMETHYL-HEXAN-3-OL TENTATIVE IDENTIFICATION STEPS EI/MS spectrum (a) and MS/MS of parent ions with $m / z, 130$ (b) and $m / z, 87$ (c).

is consistent with other data already published for pepper volatile, where an $85 \%$ quality match was considered (Cardeal et al. 2006). Here, a mass range between 40 and $415 \mathrm{u}$ was used because between this range, one precludes the monitoring of the water, air (nitrogen and oxygen) $\mathrm{m} / \mathrm{z}$ fragments, which can interfere in the spectral analysis. Additionally, this is a common scanning range for mass spectrometric analysis, when MS/MS is not used (Fernandes et al. 2003). Because of the separation power allowed by the two-dimensional gas chromatography experiment, one can expect to obtain pure compound spectra as possible coelutions are now avoidable, and at the same time, column bleed arising from siloxane groups and solvent peaks can be isolated and thus eliminated (Cardeal et al. 2006; Mateus et al. 2008). Gathering all the information obtained by the analytical and spectrometric techniques, the following compounds were also tentatively identified: acetoin, ethyl-3-hydroxybutanoate, methionol, ethyl-4-hydroxybutanoate, 2-phenylethanol, octanoic acid and decanoic acid. They are correspondently indicated in Table 1. Table 1 also shows the concentration of the identified compounds after alcoholic fermentation and after MLF carried out by indigenous bacteria and with inoculation of 
the two commercial starters. The concentration values for the compounds for which no standard was available are semiquantitative data assuming a response factor equal to one, as indicated in Table 1. Consequently, in order to maintain the consistency of the quantitation performed, all other compounds were determined considering the respective calculated response factors and not the individually calibration curves calculated. The elution order of $(R, R)+(S, S)$ butane-2,3-diol and meso-butan-2,3-diol was considered as shown according to the elution order already described elsewhere (Fernandes et al. 2003) as no chiral column and thus enantiomeric separation by GC was performed.

One can observe that the concentration in ethyl lactate, $\gamma$-butyrolactone and diethylsuccinate rises, confirming results already obtained for other varieties (Lloret et al. 2002; Pozo-Bayon et al. 2005; Ugliano and Moio 2005). Decanoic acid also experienced a rise in concentration under the same conditions. For the majority of the compounds, one observed a decrease in their concentration during MLF, and acetoin, hexanol and octanoic acid did not show any significant change. In general, these results are in agreement with those described elsewhere (Lloret et al. 2002; Fernandes et al. 2003), but for the case of butan-2,3-diol and 2-phenylethanol, one observed a reversed behavior compared with the varieties studied by others (Lloret et al. 2002; Fernandes et al. 2003). This can probably be a consequence of a different metabolic behavior of both yeast and lactic bacteria used to promote fermentations. In fact, different substrates in the presence of different microorganisms may produce different compounds.

Ethyl lactate showed the most remarkable concentration increase. This compound is one of the most important by-products of LAB metabolism. Although being also a by-product of yeast fermentation, its concentration increased about 20-fold after MLF. It is an important aroma compound, giving a broader and fuller flavor to wine; the aroma descriptor defines it as sweet, fruity, resembling pineapple with candy brown nuance (Lloret et al. 2002). $\gamma$-Butyrolactone is a by-product of $\alpha$-ketoglutarate metabolism of $O$. oeni, and its odor descriptor is defined as sweet and buttery; diethyl succinate is described as cheesy, earthy and spicy (Rocha et al. 2004). All these three compounds present a higher concentration in the wine inoculated with B1.

Esters play an important role in the fruity attributes of wine; they are produced by yeast, derived from grapes or from chemical esterification of acids and alcohols. LAB possess esterase activity, which may degrade esters during MLF; in fact, there is a drop in isoamyl acetate, ethyl octanoate and ethyl decanoate concentration, and ethyl decanoate was lowest in wines inoculated with B1 and B2.

On the other hand, concerning ethyl hexanoate, higher concentrations are observed in wines after MLF inoculated with the commercial bacteria. As MLF can increase or decrease fruity aroma in wine (Sauvageot and Vivier 1997; 
Gámbaro et al. 2001; Ugliano and Moio 2005), variations in medium-chain ester's concentration after MLF are also observed, suggesting that for the Trincadeira variety, esterase activity is involved in hydrolysis as much as in biosynthesis (Swiegers et al. 2005). According to these results, we might suspect that esterase activity in the inoculated bacteria (B1 and B2) is involved in biosynthesis of medium-chain ethyl esters and hydrolysis of long-chain ethyl esters.

Isoamyl alcohol is characterized by herbaceous, malty and harsh notes (Francis and Newton 2005; Ugliano and Moio 2005). Its concentration decreases in the wine where MLF occurred spontaneously; the concentration of 2-phenylethanol, expressed by floral notes (Rocha et al. 2004), decreased after MLF only in the B1 inoculated wines.

Other alcohols, such as 2,3-dimethyl-hexan-3-ol, propanol and isobutanol, decreased after MLF, with the last two being lowest in MLF carried out by indigenous bacteria.

Compounds such as diacetyl, acetoin and butan-2,3-diol result from citric acid metabolism. The citric acid degradation by $O$. oeni is slower than malic acid degradation. The formation and degradation of diacetyl in acetoin and 2,3-butanediol is directly related to the growth of LAB and the metabolism of sugar, malic and citric acids. Diacetyl, and hence acetoin and 2,3 butanediol, concentrations are affected by several factors such as the presence of oxygen, temperature, sulfur dioxide level and MLF duration (Swiegers et al. 2005). In the analyzed wines, acetoin showed no significant difference in its concentration, and butan-2,3-diol, the enantiomeric mixture $(R, R)+(S, S)$, present a lower concentration after MLF.

The development of MLF by indigenous bacteria or by inoculated starters shows some differences in volatile compound's concentration.

The general increase in ethyl lactate, $\gamma$-butyrolactone and diethyl succinate and the case observed with acetoin or butan-2,3-diol (all stereoisomers) indicate that the general metabolism during MLF must be similar. Nevertheless, higher values were observed for the first three compounds when B1 LAB was used, reflecting that this commercial preparation has a different behavior in developing aroma compounds for the Trincadeira variety.

The concentration of nine of the identified compounds differed between the three studied batches (C, B1 and B2) after MLF; these variations might probably correspond to a distinct wine's final quality. These results are for the first time reported for the Trincadeira variety, which also present some unique differences compared with other red wine varieties (Pozo-Bayon et al. 2005; Revel et al. 2005; Ugliano and Moio 2005), suggesting that the final bouquet of the produced wine can be influenced when Trincadeira is used for wine production, and also keeping in mind that the LAB activity should be monitored during the MLF. 


\section{CONCLUSIONS}

The Trincadeira is a very used wine variety in Portugal because is very well adapted for climate and soil conditions. Nevertheless, little is known about their influence on the volatile composition of wines containing it, and also the contribution of MLF for the volatile profile of this variety. In general, a decrease in compounds as esters and higher alcohols was observed. Ethyl lactate, $\gamma$-butyrolactone and diethyl succinate concentration increased in all the wine samples after MLF, the observed increase concentration being higher in the sample wines inoculated with B1. In contrast with other red wine varieties, butan-2,3-diol (all stereoisomers) present a decrease in its concentration, which might contribute to the bouquet of wine containing Trincadeira compared with other varieties (Fernandes et al. 2003). GC/MS is an adequate tool for tentative identification on the basis of EI spectra comparison with a library. Nevertheless, additional ionization modes, such as CI and MS/MS, may provide additional information to support the identification assignments when standards are not available, and $\mathrm{GC} \times \mathrm{GC} / \mathrm{ToF}-\mathrm{MS}$ can be used in order to obtain high spectral quality for further peak identification tasks.

\section{ACKNOWLEDGMENTS}

The authors would like to acknowledge AEB Bioquímica Portuguesa for kindly providing the enological products, and Fundação para a Ciência e a Tecnologia, Ministério da Ciência, Tecnologia e Ensino Superior for financial support (Project POCI/AGR 55432). The authors would also like to acknowledge Professor Philip Marriott from the ACROSS Laboratory at the RMIT University, Melbourne, Australia, for the GC $\times$ GC-ToF-MS facilities.

\section{REFERENCES}

ADAHCHOUR, M., BEENS, J. and BRINKMAN, U.A.T. 2008. Recent developments in the application of comprehensive two-dimensional gas chromatography. J. Chromatogr. A 1186, 67-108.

BENINCASA, C., NINO, A., LOMBARDO, N., PERRI, E., SINDONA, G. and TAGARELLI, A. 2003. Assay of aroma active components of virgin olive oils from southern Italian regions by SPME-GC/Ion trap mass spectrometry. J. Agric. Food Chem. 51, 733-741.

BOUCHONNET, S., LIBONG, D. and SABLIER, M. 2004. Low pressure chemical ionization in ion trap mass spectrometry. Eur. J. Mass Spectrom. 10(4), 509-521. 
CABRITA, M.J., TORRES, M., PALMA, V., ALVES, E., PATÃO, R. and COSTA FREITAS, A.M. 2008. Impact of malolactic fermentation on low molecular weight phenolic compounds. Talanta 74, 1281-1286.

CANE, P. 1990. Il controlo della qualita dei vini mediante HPLC: Determinazione degli acidi organici. L'enotecnico 26, 69-72.

CARDEAL, Z.L., GOMES DA SILVA, M.D.R. and MARRIOTT, P.J. 2006. Comprehensive two-dimensional gas chromatography/mass spectrometric analysis of pepper volatiles. Rapid Commun. Mass Spectrom. 20, $2823-2836$.

CARERI, M., BIANCHI, F. and CORRADINI, C. 2002. Recent advances in the application of mass spectrometry in food-related analysis. J Chromatogr. A 970, 3-64.

CULLERÉ, L., CACHO, J. and FERREIRA, V. 2006. Validation of an analytical method for the solid phase extraction, in cartridge derivatization and subsequent gas chromatographic-ion trap tandem mass spectrometric determination of 1-octen-3-one in wines at ng/L level. Anal. Chim. Acta $563,51-57$.

FERNANDES, L., RELVA, A.M., GOMES DA SILVA, M.D.R. and COSTA FREITAS, A.M. 2003. Different multidimensional chromatographic approaches applied to the study of wine malolactic fermentation. J. Chromatogr. A 995, 161-169.

FRANCIS, I.L. and NEWTON, J.L. 2005. Determining wine aroma from compositional data. Aust. J. Grape Wine Res. 11(2), 114-126.

GÁMBARO, A., BOIDO, E., ZLOTEJABLKO, A., MEDINA, K., LLORET, A., DELLACASA, E. and CARRAU, F. 2001. Effect of malolactic fermentation on the aroma properties of Tannat wine. Aust. J. Grape Wine Res. 7(1), 27-32.

GINDREAU, E., KEIM, H., DE REVEL, G., BERTRAND, A. and LONVAUD-FUNEL, A. 2003. Use of direct inoculation malolactic starters: Settling, efficiency and sensorial impact. J. Int. Sci. Vigne Vin. 37(1), 51-57.

KARAGIANNIS, S., ECONOMOU, A. and LANARIDIS, P. 2000. Phenolic and volatile composition of wines made from Vitis vinifera $\mathrm{cv}$. Muscat lefko grapes from the island of Samos. J. Agric. Food Chem. 48(11), 5369-5375.

KARÁSEK, P., PLANETA, J., OSTRÁ, E.V., MIKEOVÁ, M., GOLIÁS, J., ROTH, M. and VEJROSTA, J. 2003. Direct continuous supercritical fluid extraction as a novel method of wine analysis: Comparison with conventional indirect extraction and implications for wine variety identification. J. Chromatogr. A 1002(1-2), 13-23.

LLORET, A., BOIDO, E., LORENZO, D., MEDINA, K., CARRAU, F., DELLACASSA, E. and VERSINI, G. 2002. Aroma variation in Tannat 
wines: Effect of malolactic fermentation on ethyl lactate level and its enantiomeric distribution. Ital. J. Food Sci. 14(2), 175-180.

LONVAUD-FUNEL, A. 1999. Lactic acid bacteria in the quality improvement and depreciation of wine. Antonie Van Leeuwenhoek 76, 317-331.

MATEUS, E.P., GOMES DA SILVA, M.D.R., RIBEIRO, A.B. and MARRIOTT, P.J. 2008. Qualitative mass spectrometric analysis of the volatile fraction of creosote-treated railway wood sleepers by using comprehensive two-dimensional gas chromatography. J. Chromatogr. A 1178, 215-222.

MILLER, J.C. and MILLER, J.N. 1993. Statistics for Analytical Chemistry, 3rd Ed., Chichester, Ellis Horwood.

ORTEGA-HERAS, M., GONZÁLEZ-SANJOSÉ, M.L. and BELTRÁN, S. 2002. Aroma composition of wine studied by different extraction methods. Anal. Chim. Acta 458(1), 85-93.

OSBORNE, J.P., ORDUNA, R.M., PILONEL, J.G. and LIU, S.-Q. 2000. Acetaldehyde metabolism by wine lactic acid bacteria. FEMS Microbiol. Lett. 191(1), 51-55.

POZO-BAYON, M.A., ALEGRIA, E.G., POLO, M.C., TENORIO, C., MARTIN-ALVAREZ, P.J., CALVO DE LA BANDA, M.T., RUIZLARREA, F. and MORENO-ARRIBAS, M.V. 2005. Wine volatile and amino acid composition after malolactic fermentation: Effect of Oenococcus oeni and Lactobacillus plantarum starter cultures. J. Agric. Food Chem. 53, 8729-8735.

REVEL, G., BLOEM, A., AUGUSTIN, M., LONVAUD-FUnEL, A. and BERTRAND, A. 2005. Interaction of Oenococcus oeni and oak wood compounds. Food Microbiol. 22, 569-575.

ROCHA, S.M., RODRIGUES, F., COUTINHO, P., DELGADILLO, I. and COIMBRA, M.A. 2004. Volatile composition of Baga red wine. Assessment of the identification of the would-be impact odourants. Anal. Chim. Acta 513, 257-262.

ROCHA, S.M., COUTINHO, P., BARROS, A., DELGADILlO, I. and COIMBRA, M.A. 2006. Rapid tool for distinction of wines based on the global volatile signature. J. Chromatogr. A 1114(2), 188-197.

SAUVAGEOT, F. and VIVIER, P. 1997. Effects of malolactic fermentation on sensory properties of four Burgundy wines. Am. J. Enol. Vitic. 48(2), 187-192.

SWIEGERS, J.H., BARTOWSKY, E.J., HENSCHKE, P.A. and PRETORIUS, I.S. 2005. Yeast and bacterial modulation of wine aroma and flavour. Aust. J. Grape Wine Res. 11(2), 139-174.

UGLIANO, M. and MOIO, L. 2005. Changes in the concentration of yeastderived volatile compounds of red wine during malolactic fermentation with four commercial starter cultures of Oenococcus oeni. J. Agric. Food Chem. 53, 10134-10139. 